\title{
ALLEGED USEFULNESS OF THE GEORGE YOUNG TEST IN THE DETECTION OF GLAUCOMA*
}

\author{
BY \\ J. GLOSTER AND R. A. WEALE \\ Departments of Experimental Ophthalmology and Physiological Optics, Institute of Ophthalmology, University \\ of London
}

THE incidence of unsuspected simple glaucoma is about 2 per cent. of the population over the age of 40 years. For the detection of these cases a simple method of testing, which could be applied quickly to large numbers of subjects, is obviously desirable. The George Young test is sometimes mentioned in this connexion (Hollis, 1963). It was described in 1918 by its originator (Young, 1918), who regarded it as a test of the threshold of light and maintained that "in early glaucoma the light sense was very much affected". It is to be noted that Young stated that the test was also useful in the recognition of tobacco amblyopia and that it detected small central scotomata, so that he made no claim that it was specific for glaucoma.

The George Young test is based on the brightness discrimination of the eye and consists of discs $15 \mathrm{~mm}$. in diameter of graduated greyness, printed severally on white sheets of paper which are bound together to form a small album. Sometimes the grey tone is replaced by colour, but as no one seems to have studied or specified the requisite reflection factors we should like to disregard the chromatic aspect. The rationale behind the test is the belief that, in glaucoma, the brightness discrimination is impaired (Ourgaud and Etienne, 1961a), and hence that the glaucomatous eye will be able to discern the intensely grey discs but will fail with the pale ones.

In order to corroborate the findings of the test it was thought desirable to use another method of assessing the brightness discrimination of the eye. For this purpose a "contrast" test was devised consisting of eight white squares placed round a circle on a black background. The squares were backed with three layers of white paper and illuminated from behind with a $15 \mathrm{w}$. opal glass lamp to ensure uniform illumination. Each white square contained three black letters (only two of which occurred twice), which did not form words and which subtended at the eye an angle of some $15 \mathrm{~min}$. of arc. The squares were covered with neutral filters which increased in density from square to square in a clockwise direction. The squares were numbered from 1 to 8 , starting at the 12 o'clock position; the white square at 3 o'clock transmitted one-quarter of the light given at 12 o'clock, that at 6 o'clock transmitted only one-sixteenth, and so on. Thus the brightness contrast between the letters and their backgrounds diminished from the low-numbered to the highnumbered squares in a clockwise direction. The squares were viewed through a tube $50 \mathrm{~cm}$. long, the outside of which was painted white and the inside black. One end of the tube fitted closely around the circle of squares excluding ambient light whilst the other end was covered by a white disc perforated at the centre with an aperture $1 \mathrm{~cm}$. in diameter through which the subject looked. 
In order to compare the results of the contrast test with those of the George Young test, the grey discs in the latter were also numbered, 1 denoting the most intense and 8 the palest. The ambient room illumination was 3 to 5 e.f.c. for both tests, so that the eyes were adapted to a high mesopic level, the object of painting the "contrast" apparatus white being to ensure that the patient remained adapted to the ambient level till the last moment before taking a reading.

Our patients were divided into three groups: non-glaucomatous below 40 years of age; non-glaucomatous over 40 years of age; and chronic glaucomatous, including both closed-angle and simple cases, diagnosed on the basis of tonometric and tonographic findings in addition to the usual clinical criteria. It was essential to include a group comparable in age with the glaucomatous group, since glaucoma is relatively rare in young eyes and brightness discrimination does, in fact, vary with age (Weale, 1963). It should be noted that the non-glaucomatous eyes in patients over 40 years of age were not necessarily completely healthy eyes. In none of them was there any gross disease, but some had early lens opacities or mild atherosclerotic changes in the retinal vessels; thus they formed a group, comparable in general condition with the glaucomatous eyes, but showing no evidence of glaucoma, as far as full and careful investigation allowed one to say. At the time of examination, the intra-ocular pressure in the majority of the glaucomatous eyes was below $30 \mathrm{~mm} . \mathrm{Hg}$ as a result of surgery or miotic therapy.

Visual acuities for distance and near were recorded and only eyes in which the visual acuity was at least $6 / 18$ were included in the tests. The pupillary size was also noted because brightness discrimination varies with the level of retinal illumination, the latter being determined partly by the effective entrance pupil (Ourgaud and Etienne, 1961b; Weale, 1963). Other things being equal, brightness discrimination is, in general, lower at low than at high luminance levels and may therefore be reduced under miosis.

For both tests, the patient wore his reading correction. In the George Young test, one eye was covered and the patient was shown the page with the palest grey disc on it and was asked whether or not he saw a spot. If not, discs of increasing intensity were presented until he did see a spot. This was recorded, using the notation given above, and the test was repeated on the second eye. The patient remained seated and was then asked to look down the tube of the apparatus for the contrast test and to read the letters, starting with those in the square at 12 o'clock and then moving on to the other squares in a clockwise direction. A note was made of the highest-numbered square in which he could recognize two out of the three letters. The test was then repeated on the other eye.

The number of subjects and eyes in each group and their average ages are given in the Table (opposite). Fig. 1 (opposite) compares the three groups with respect to pupillary diameter and visual acuity.

The pupils tended to be smaller in non-glaucomatous eyes over 40 years of age, as compared with those under 40 , this being due to senile miosis. In the glaucomatous group, pupillary diameters were reduced even further owing to the use of miotics by a large proportion of these patients. Visual acuities did not differ significantly between the glaucomatous group and the non-glaucomatous group over 40 years of age, although both showed some evidence of senile deterioration in 


\begin{tabular}{l|l|c|c|c}
\hline \multicolumn{2}{c|}{ Series } & $\begin{array}{c}\text { No. of } \\
\text { Individuals }\end{array}$ & $\begin{array}{c}\text { Average Age } \\
\text { (yrs) }\end{array}$ & $\begin{array}{c}\text { No. of } \\
\text { Eyes }\end{array}$ \\
\hline \multirow{2}{*}{ Non-glaucomatous Subjects } & Under 40 yrs & 14 & 28 & 27 \\
\cline { 2 - 5 } & Over 40 yrs & 21 & 56 & 32 \\
\hline Patients with Chronic Glaucoma & 26 & 59 & 35 \\
\hline
\end{tabular}
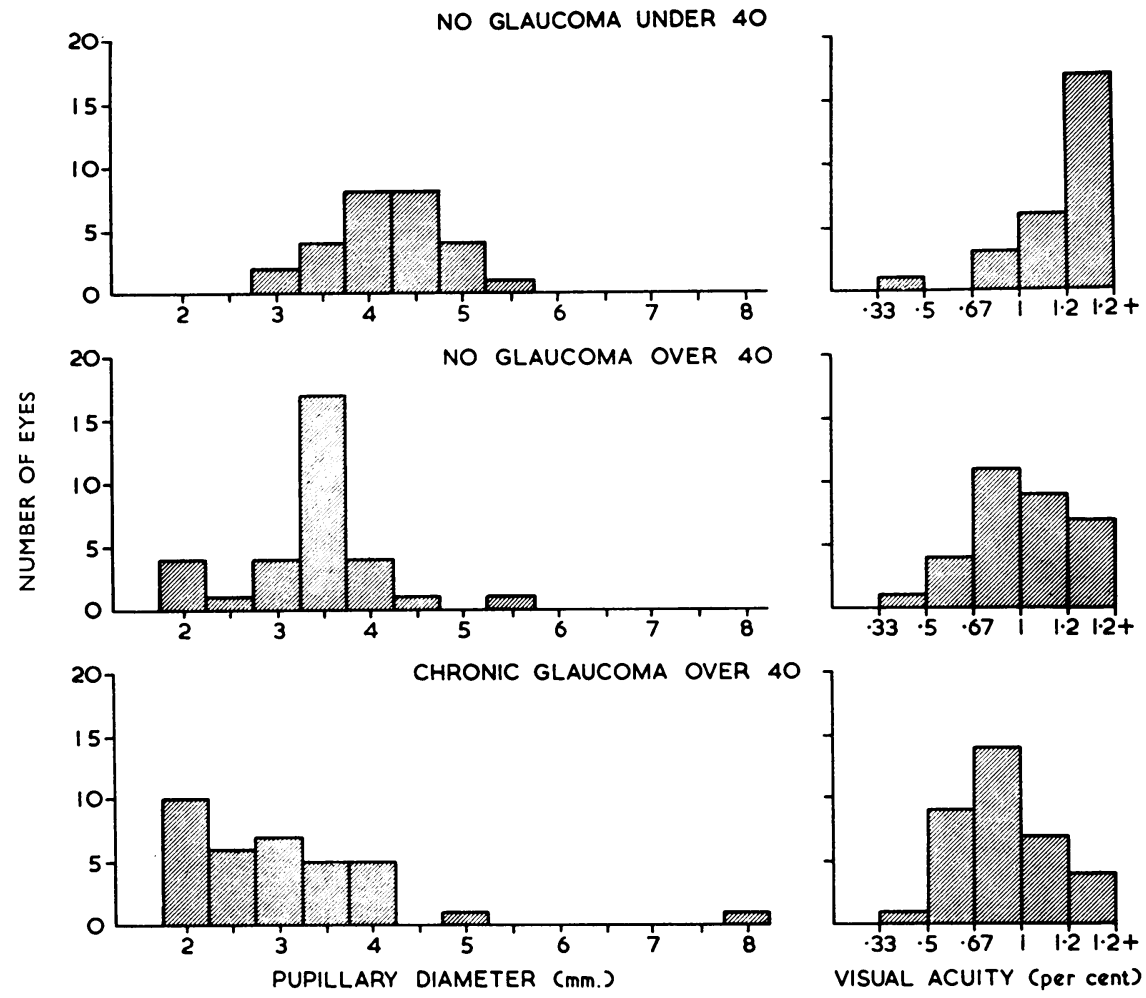

Fig. 1.-Pupillary diameter and visual acuity in three groups of subjects.

acuity when compared with the younger group. (Following recent practice, e.g. in the United States, visual acuity is expressed as a percentage: thus $6 / 6=1.0$; $6 / 12=0 \cdot 5$, etc.).

The results of the contrast test and the George Young test are shown in Fig. 2 (overleaf).

Both tests showed a small diminution in contrast discrimination by patients over 40 years of age as compared with those under 40 ; this may be attributed to the senile miosis already noted. At the same time it is clear that there was no substantial difference between the results for the older non-glaucomatous group and those for the glaucomatous patients, although a worse contrast discrimination by the latter might have been expected purely on account of the more marked miosis in that group. 


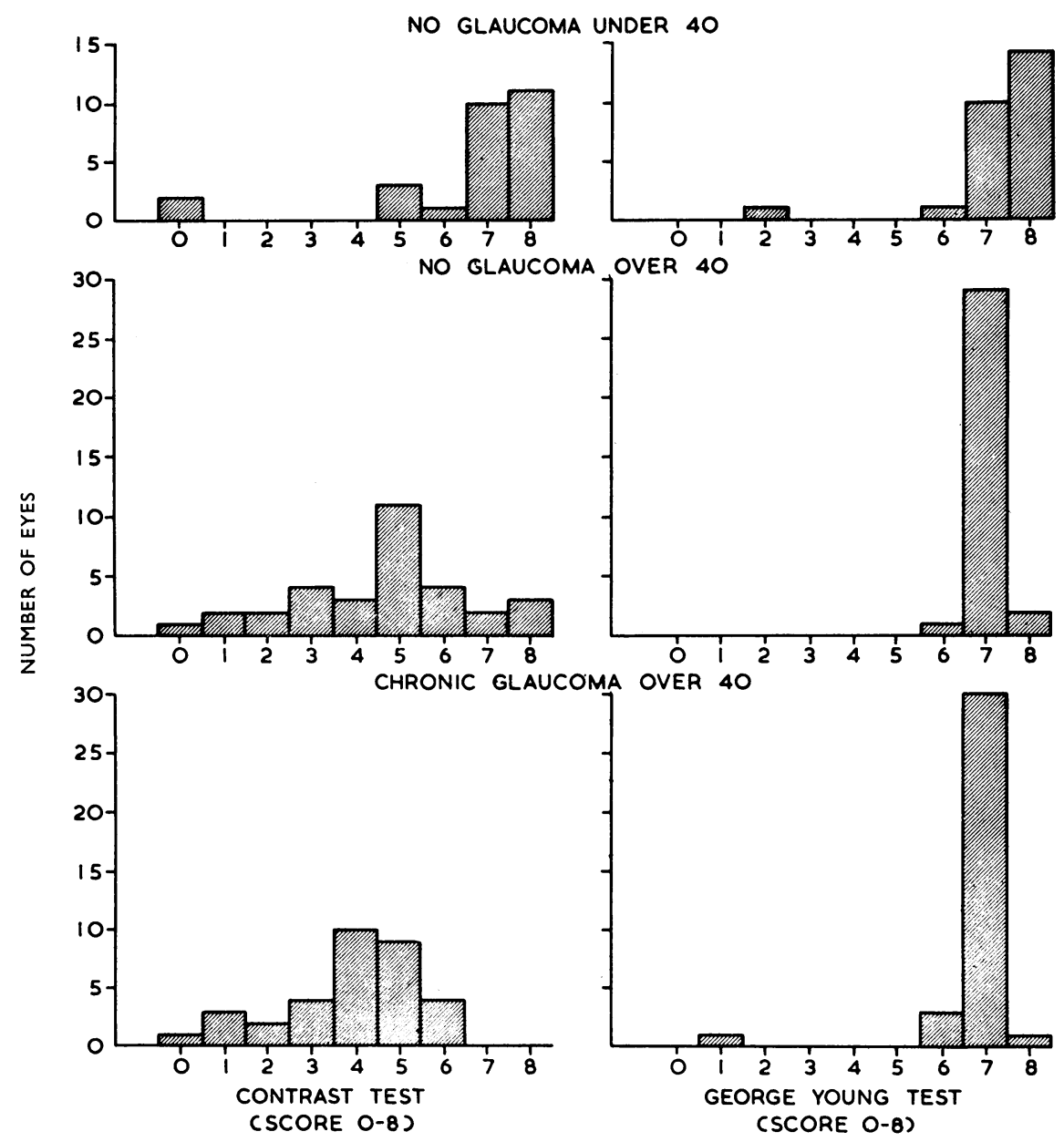

FIG. 2.-Results of contrast and George Young tests in three groups of subjects.

These findings do not encourage the view that such tests as those discussed here can distinguish between normal and glaucomatous eyes. This conclusion is at variance with that reached in another study (Law, 1959), in which the possible effect of pupillary size does not appear to have been taken into account. Also, it should be borne in mind that none of our glaucomatous patients had a marked elevation of intra-ocular pressure when examined, and it is possible that different results might have been obtained in a group of patients with high ocular tensions. Such patients could easily be discovered by routine tonometry, which would provide far more positive evidence of glaucoma than is to be expected from any test based upon the detection of differences in brightness discrimination.

Although, as a result of treatment our patients had normal or only slightly raised ocular tensions they showed considerable variations in the stage to which the glaucomatous process had progressed. The number of patients was too small to allow a comprehensive analysis but, if the stage of the disease were judged from the extent 
of the defect in the field of vision, it was quite clear that there were no correlation between the latter and performance in the tests. This observation adds weight to our conclusion that the clinical value of the George Young test in the detection of glaucoma is negligible.

\section{REFERENCES}

Hollis, P. (1963). Optician, 145, 252.

LAW, F. W. (1959). Trans. ophthal. Soc. U.K., 79, 33.

OURGAUD, A. G., and ÉTIENNE, R. (1961a). "L'exploration fonctionelle de l'oeil glaucomateux", vol. 2. Masson, Paris.

- (1961b). Ibid., vol 1.

Weale, R. A. (1963). "The Aging Eye". Lewis, London.

YounG, G. (1918). Trans. ophthal. Soc. U.K., 38, 279. 